\title{
Semiárido brasileiro: um histórico de secas e degradação socioambiental
}

\section{The Brazilian semiarid Northeast: a history of drought and environmental degradation}

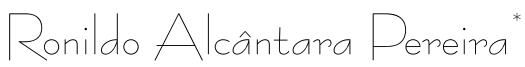

Introdução

As navegações dos séculos XV e XVI e a ocupação da América portuguesa foram consequência direta de vários fatores inerentes às transformações do Velho Mundo, dos quais, três podem ser considerados determinantes: a relativa estabilidade no pós-guerra da Reconquista; o conhecimento acumulado pela Península Ibérica em Cartografia e navegação, advindo também da própria expansão árabe; e a necessidade de alargamento do território europeu, através de novas rotas marítimas comerciais, em um período de demandas crescentes, reprimidas durante o feudalismo.

Assim, a colonização da costa leste do Continente sul-americano, como produto do expansionismo europeu se efetivou, a priori, numa faixa costeira marginal ao Atlântico, nunca superior a cem quilômetros de largura, por intermédiodo processo de exploração das terras recém-descobertas, como resultado da expansão mercantil europeia e inaugurando a fase capitalista, que coincidiu com a expansão do mercado mundial ${ }^{1}$.

A ausência do principal objetivo do colonizador, o metal precioso, fez com que a Coroa portuguesa consolidasse a ocupação por meio do extrativismo vegetal e, posteriormente, da atividade canavieira, aproveitando-se da excelente qualidade

* Geógrafo, Doutorando do Programa de Pós-graduação em Recursos Naturais da UFCG, Campus I, Campina Grande - PB. E-mail: ronildo@dec.ufcg.edu.br

${ }^{1}$ SODRÉ, N. W. Radiografia de modelo. Rio de Janeiro: Bertrand Brasil, 1987. 
do solo, clima adequado e proximidade com os portos, para escoar a produção, cimentando o principal empreendimento português, no além-mar, o Engenho. Dessa forma, o açúcar passou a ser produzido nas terras recém-descobertas, consolidando o primeiroobjetivo da colonização na forma de aporte de recurso ${ }^{2}$.

Dada a importância econômica que o açúcar adquiriu, a Metrópole cuidou em proteger o espaço ocupado pela canade-açúcar contra a concorrência de qualquer outra atividade produtiva. Com essa ação, forçou-se a marcha para o interior do continente, ensejando o povoamento e a prática de outras culturas, as quais serviriam de apoio ao engenho, a exemplo da pecuária, que supriu o setor canavieiro de pele, carne e animais para o trabalho. Estava, assim, criado o outro empreendimento produtivo que cristalizou a presença europeia no interior do continente, o Curral ${ }^{3}$.

Segundo esses autores, a pecuária nordestina ganhou o Sertão através das regiões ribeirinhas dos rios, baseando-se no sistema decriação extensivo e, por necessidade, provocou a extração do sal destinado à fabricação do charqueutilizado na alimentação da população escrava do engenho, além de ser responsável pelo povoamento do Semiárido nordestino.

As dificuldades para a ocupação do Sertão contrastou com relativa facilidade encontrada na costa devido a aspectos como o relevo, o ataque dos povos nativos ${ }^{4}$, assim como as condições climáticas inóspitas. Mesmo assim, utilizando-se do leito dos rios, o colonizador transpôs os obstáculos naturais e deu início ao processo de povoamento ${ }^{5,6}$.

${ }^{2}$ BECKER, K. B. e EGLER, C. A. Brasil: Uma Nova Potência Regional na Economia Mundo. 3. ed. Rio de Janeiro: Bertrand Brasil, 1998. 272p. (Coleção Geografia)

${ }^{3}$ Ibidem.

${ }^{4}$ A resistência oferecida pela população estabelecida, para fazer frente ao colonizador/invasor, foi desprovida de articulação devido à falta de organização destes povos, vivendo, à época, ainda como coletores. A reação mais profícua só viria após a expansão da ocupação, após os primeiros cento e cinquenta anos sob a denominação de confederação dos Tamoios.

${ }^{5}$ JOFILLY, I. Notas Sobre a Parahiba. Livro I. Rio de Janeiro: Thesaurus Editora, 1892.

${ }^{6} \mathrm{~A}$ despeito de o autor tratar o semiárido como uma área desprovida da presença de uma população que pudesse oferecer maior resistência ao colonizador. Esse fato pode ser atribuído ao contexto da época em que a obra foi escrita. Contudo, muito do que preconizou Irineu Jofilly ainda se encontra bastante atual, como, por exemplo, providências deveras eficazes para convivência com o fenômeno da estiagem, tão presente ainda hoje. 
A partir daí, meados do Século XVII, desencadeou-se um contínuo processo de exploração dos recursos do semiárido brasileiro, que nos dias atuais, beira a exaustão, mas também uma busca incessante por formas de convivência com as adversidades do clima, personificada no fenômeno das secas.

A designação de seca é comum para referir-se a um período prolongado de baixa pluviosidade ou sua ausência, em que a perda de umidade do solo é superior a sua reposição. Esse evento, por sua vez, pode ser considerado como um dos fenômenos naturais de maior ocorrência e impacto no mundo ${ }^{7}$. Esse evento cíclico conta com registro a partir de meados do século XVI e, a cada ocorrência, degrada, dizima ambiente, populações e rebanhos, tendo sido a de 1877 a de maior espectro ${ }^{8}$.

No interior da Capitania Real de Paraíba, a microrregião dos Cariris Velhos, chamada à época de Cariris de Fora, a partir dos currais, surgiu uma pequena concentração urbana que viria a se tornar o berço da colonização do sertão, e ganharia a denominação de São João dos Cariris de Fora. Ali, concentrou-se uma aristocracia rural tão sólida que tinha assento cativo na Câmara imperial, oriunda de algumas famílias abastadas ali radicadas e cuja principal atividade era a pecuária extensiva, de largo reconhecimento como ambientalmente degradante.

Tomando como base esse exemplo de influência e poder, em todo o interior do semiárido, as elites souberam como utilizar as mazelas da seca e, posteriormente, como tirar proveito das providências para sua mitigação. Com isso, surgiram nesta área alguns aspectos que se conservam até os dias atuais: degradação ambiental decorrente da atividade pecuária, desigualdade social e concentração de terra, por meio de uma estrutura agrária perversa ${ }^{9}$.

\footnotetext{
${ }^{7}$ KOBIYAMA, M.; MENDONÇA, M.; MORENO D. A. MARCELINO, I. P. V. de.; MARCELINO, E.; BRAZETTI, L. L. P., GOERL, R. F.; MORELI, G. S. F. e RUDORFF, F. M. Prevenção de Desastres Naturais: conceitos básicos. Curitiba: Ed. Organic Trading, 2006.

${ }^{8}$ VILLA, Marco Antonio. Vida e morte no Sertão: história das secas no Nordeste nos Séculos IX e XX. 1. ed. São Paulo: Ática, 2000.

${ }^{9}$ PEREIRA, R. A. Impactos ambientais decorrentes das condições antroponaturais no município de São João do Cariri - PB. Campina Grande: UFCG, 2008. 106p. (Dissertação de Mestrado).
} 
Embora se reconheçam os avanços galgados pela região em infraestrutura e modernização da indústria como um todo, o mesmo não se pode dizer do setor rural e, menos ainda, com relação à melhoria na qualidade de vida de grande parcela da população de baixo poder aquisitivo, considerando que o modelo que guiou as políticas públicas visava o crescimento econômico, restrito à área costeira e não considerado sinônimo de desenvolvimento, ao menos para muitos estudiosos do assunto.

A partir do exposto, este ensaio teórico procura decompor, ainda que de forma simplificada, os fatores que originaram a povoação, as condições climáticas da área, as condições de vida da população e as metas que justificaram a criação dos órgãos de combate as secas, bem como as consequências de algumas de suas ações sobre a conjuntura socioeconômica e ambiental do semiárido, assim como o papel desempenhado pelo poder local no desfecho destas políticas. Como estratégia metodológica, foi realizado um levantamento bibliográfico em publicações de maior importância no tocante ao tema e, a partir daí, foi realizada uma análise crítica, de modo a alcançar os objetivos propostos.

\section{Secas no semiárido brasileiro:questão técnica ou social?}

Há muito se reconhece que as secas periódicas que castigam a zona semiáridado Nordeste assumem dimensões de calamidade pública devido à situaçãode pobreza em que vive a maior parte desta classe menos abastada ${ }^{10}$. No entanto, a situação derelativa precariedade em que vive a maior parte da população decorre de fatores que vão além dos condicionantes geográficos (climáticos).

Mas o que é a seca, esse fenômeno tão impactante, do ponto de vista estritamente físico?A seca é um fenômeno climático que afeta drasticamenteuma região, além de provocar graves danoseconômicos e sociais. Corresponde a uma característicatemporária do clima de uma região, provocadapela ocorrência de precipitações pluviométricas abaixoda normal, por certo período de tempo, o que nãodeve ser confundido com aridez que é

${ }^{10}$ DUQUE, José Guimarães. O Nordeste e as lavouras xerófilas. Fortaleza: Banco do Nordeste, 1973. 
uma característicapermanente do clima, resultante de normais pluviométricasmuito baixas ${ }^{11}$.

Para estes autores, de modo geral as secas são designadas em funçãodos fatores naturais que as causam. Dentre outros,pode-se citar o clima da região, as distribuiçõesespacial e temporal das precipitações, a capacidadede armazenamento de água pelo solo, as flutuaçõesdos lençóis freáticos subterrâneos e a qualidade deágua armazenada a superficie ou corrente, o quetorna extremamente dificil a formulação de umadefinição consensual deseca.

Existem diversas maneiras de se definir seca, dependendo principalmenteda temática da abordagem. Essas abordagens podem ser relacionadas à precipitação, agricultura, hidrologia e à área socioeconômica. Sendoassim, vários autores ${ }^{12},{ }^{13}$ definiram quatro tipos de secas: meteorológica,agrícola, hidrológica e socioeconômica. Embora as secas estejam classificadas nesses quatro tipos, todas sãooriginadas da deficiência de precipitação, que resulta na falta de águapara o desenvolvimento de atividades ou para a sobrevivência dos seresvivos ${ }^{14}$.

Além de abrangente, silenciosa e de difícil predição para os padrões tecnológicos disponíveis na pesquisa brasileira, adicionada à falta de vontade politica para resolvê-la, apresenta-se sob quatro tipos reconhecidos ${ }^{15}$, cujas características são definidas como: (i) meteorológica: é expressa apenas com base no grau de securae na duração do período seco comparados a algum estado normal,ou seja, é caracterizada pelo déficit da precipitação em relação ao valor normal; (ii) hidrológica: esse tipo de seca está relacionado com a redução dos níveis médios de água

\footnotetext{
${ }^{11}$ AZEVEDO, P. V. de; SILVA, V. P. R. da. Índice de seca para a microrregião do agreste da Borborema, no estado da Paraíba. Revista Brasileira de Meteorologia, 9 (1). p 66-72, 1994.

${ }^{12}$ BYUN, H. R.; WILHITE, D. A. Objective quantification of drought severity and duration. Journal of Climate, Boston, v. 12, n. 9, p. 2747-2756, Sept. 1999.

${ }^{13}$ MCKEE, T. B.; DOESKEN, N. J.; KLEIST, J. The relationship of drought frequency and duration to the time scales. In: CONFERENCE ON APPLIED CLIMATOLOGY, 8. 1993, Anhaeim, CA. Proceedings. Boston: American Meteorological Soceity, 1993. p. 179-184.

${ }^{14}$ WILHITE, D. A. Drought. In: HOLTON, J. R.; PYLE, J. A.; CURRY, J. A. (Ed.). Encyclopedia of atmospheric sciences. New York: Elsevier, 2003. p. 650-658.

${ }^{15}$ FERNANDES, Diego S. F.; HEINEMANN, A. B.; PAZ, R. L. da.; AMORIM, A. de O.; CARDOSO, A. S. Índices para a Quantificação da Seca. Santo Antônio de Goiás, GO: EMBRAPA, 2009.
} 
em reservatórios de superfície e subterrâneos por um determinadoperiodo de tempo, podendo ser de dias, semanas, meses ou anos sucessivos; (iii) agrícola: as combinações dos tipos de seca meteorológica e hidrológica estãodiretamente ligadas aos impactos na agricultura, ocasionando, assim, aseca agrícola. Esse tipo de seca está basicamente associado à disponibilidadede água no solo para suportar o crescimento e desenvolvimento das plantas; (iv) a seca socioeconômica está relacionada com o impactosobre as atividades humanas, incluindo os impactos diretos eindiretos na produção agrícola e outras atividades econômicas. Essa versão é, talvez, a que ganha mais notoriedade, pois seu espectro vai muito além de sua área de abrangência.

O fenômeno das secas pode ser diagnosticado com base em uma série históricade dados meteorológicos, por meio de índices quantificadores de secase análises estatísticas.

A alta variabilidade espacial e temporal da pluviometria no semiárido nordestino torna dificil a previsibilidadee o monitoramento das secas, mais ainda asua intensidade e seus efeitos sobre a economia regional.Esforços nesse sentido têm se concentrado no estabelecimentode índices de seca que, convenientemente interpretados, podem fornecer informaçõesvaliosas para o planejamento agrícola e o gerenciamentodas disponibilidades hídricas da região. Contudo, a despeito das ferramentas disponíveis para sua prevenção, poucas são as ações com base nestes estudos, os quais poderiam apontar saída para tamanha problemática ${ }^{16}$.

Quando ocorre uma seca prolongada,a produção agrícola se perde, a pecuária fica estagnada ou dizimada e asreservas de água de superfície se esgotam. Nessas condições, a parcela mais pobre da população rural torna-se inteiramente vulnerável ao fenômeno. De acordo com a história, a sobrevivência daqueles contingentes de pessoas tem dependido das políticas oficiais de socorro, do recurso à emigração paraoutras regiões, ou ainda, para as áreas urbanas do próprio Nordeste ${ }^{17}$.

\footnotetext{
${ }^{16}$ AZEVEDO, P. V. de; SILVA, V. P. R. da. Índice de seca para a microrregião do agreste da Borborema, no estado da Paraíba. Revista Brasileira de Meteorologia, 9 (1): 66-72, 1994.

${ }^{17}$ DUARTE, J. J. A nova paisagem do Semiárido no contexto da modernização: o caso da Algaroba. Revista da Adufpb. João Pessoa, 2000.
} 
Deve ser destacado, todavia que, quando o grosso da literatura pertinente ao tema aborda a questão das secas, inevitavelmente ela é associada ao Nordeste como um todo, o que não corresponde à verdade.

O Nordeste ${ }^{18}$ éuma dasregiões geográficas maisdiscutidas do país, apesar de ainda ser a menos conhecida. Com frequência, sua área éassociada ao fenômeno climático das secas e das consequências sobre a população local; entretanto, nem todo o Nordeste é castigado pelaestiagem e, por esse motivo e para melhor administrar tal fato, o Governo Federal criou, por intermédio da Lei 1.348/51, a área denominada de Polígono das Secas, ou mais comumente, de Semiárido, cujo território de abrangência corresponde a $85 \%$ da macrorregião nordestina.

Os critérios utilizados para a delimitação geográfica do semiárido eram baseados nas precipitações pluviométricas iguaisou inferiores a $800 \mathrm{~mm} /$ ano. Com essa característica climática,osmunicípios eram inseridos na área de atuação, tanto do Departamento Nacional de Obras Contra as Secas (DNOCS), quanto, posteriormente, na Superintendência de Desenvolvimento do Nordeste - (SUDENE), órgãos que mais tarde se juntariam ao Banco do Nordeste (BNB) e Ministérios, numa espécie de cruzada contra os efeitos do fenômeno da estiagem e suas consequências.

\section{Evolução da demarcação do Polígono das Secas e os aspectos fisiográficos do Semiárido brasileiro}

A região Nordeste ocupa uma área de $1.539 .000 \mathrm{~km} 2$, correspondente a $18 \%$ do território brasileiro, e abriga uma população equivalente a $29 \%$ do total nacional. Nesta área, vive metade da população pobre do país e, do ponto de vista dos aspectos geográficos, a região mostra-se bastante heterogênea, apresentando grandevariedade de situações físico-climáticas, acabando por dificultar parte das iniciativas para mitigar os efeitos das estiagens cíclicas ${ }^{19}$.

\footnotetext{
${ }^{18}$ ANDRADE, M. C. de. A terra e o homem no Nordeste. 7. ed. São Paulo: Cortez, 2005

${ }^{19}$ DUARTE, Renato. Pobreza, desigualdad social y ciudadanía: los límites de las políticas sociales em América Latina. In: CLACSO, A. Z. (Org.). Consejo Latinoamericano de Ciencias Sociales. Ciudad Autónoma de Buenos Aires, Argentina. 2001.
} 
Inserida neste imenso território está a zona semiárida,que, além da sua extensão de $882.000 \mathrm{~km}^{2}$ (cerca de 60\%), particulariza-se por ser castigada periodicamente por secas, as quais podem ocorrer sob a forma de drástica diminuição ou de concentração espaciale/ou temporal da precipitação pluviométrica anual. Quando ocorre uma grandeseca, a produção agrícola se perde, a pecuária é debilitada ou dizimada e as reservas de água de superficie se esgotam.

O Polígono das Secas foi delimitado inicialmente pela Lei $1.348 / 51^{20}$. Essa delimitação foi alterada por cerca de uma dezena de vezes, satisfazendo sempre aos critérios políticos em vez dos ecológicos. Até o ano de 1995, os parâmetros utilizados para a delimitação geográfica do semiárido eram baseados nas precipitações pluviométricos inferiores a $800 \mathrm{~mm} /$ ano. Com essa característica climática, os municípios eram inseridos na área de atuação da Superintendência de Desenvolvimento do Nordeste - SUDENE.

A última atualização dos municípios pertencentes ao Semiárido foi feita em 1995, pela SUDENE, ampliando os critérios de classificação, a partir de três variáveis climáticas ao invés de uma precipitação pluviométrica média anual; índice de aridez de até 0,5 , calculado pelo balanço hídrico que relaciona as precipitações e a evapotranspiração potencial, no período entre 1961 e 1990; e risco de seca maior que 60\%, tomando-se por base o período entre 1970 a $1990^{21}$.

Com a extinção da mencionada Autarquia, passou para o Ministério da Integração Nacional a responsabilidade de posicionar-se acerca dos pleitos de inclusão dos municípios interessados em dispor de tratamento diferenciado das políticas de crédito e beneficios fiscais conferidos àquela parcela do território brasileiro.

Sob esta nova classificação, a área do Polígono das Secas, Figura 1, ampliou-se de $892.309,4$ para $969.589,4 \mathrm{~km}^{2}$, sendo

\footnotetext{
${ }^{20}$ REBOUÇAS, A da C. Água na Região Nordeste: desperdício e escassez. Estudos Avançados, v. 11, no. 29, 1997, p. 127-154.

${ }^{21}$ BRASIL, MINISTÉRIO DA INTEGRAÇÃO NACIONAL. Cartilha Nova Delimitação do Semiárido, Brasília, 2005. Disponível em: <http://www.integracao.gov.br>. Acesso em: 18 de fevereiro de 2011.
} 
composta por 1.135 municípios, com uma população de cerca de 21.000 .000 pessoas.

Figura 1 - Localização da área de abrangência do polígono das secas, após a nova delimitação realizada pela SUDENE em 1995.

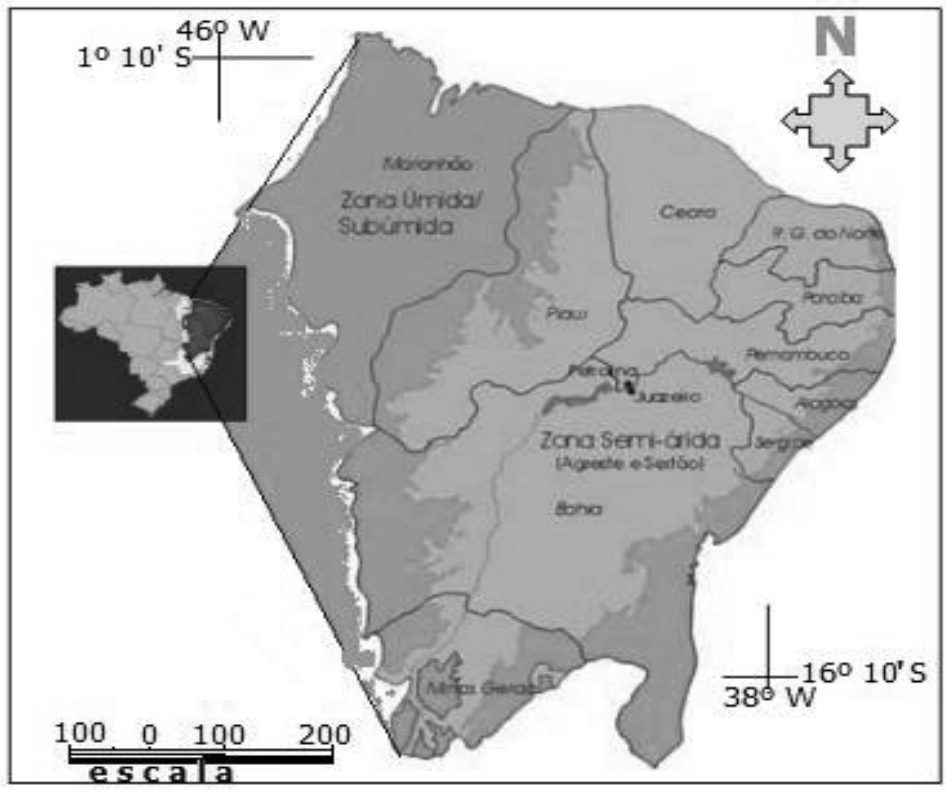

Fonte: modificado de fontes diversas ${ }^{22}$.

O clima no semiárido tem papel preponderante e é classificado por Köppen como quente e úmido (Bsh), caracterizado por uma baixae irregular pluviosidade concentrada em apenas três meses do ano, na faixa compreendida entre 300 e $900 \mathrm{~mm} /$ ano. As temperaturas médias anuais são da ordem de 26 a $29^{\circ} \mathrm{C}$. Ainda segundo os critérios adotados por Köppen às designações das letras, tem-se o seguinte: B significa que a evapotranspiração potencial média é maior que a precipitação média anual, nãohavendo, portanto, excedente de água, daí o porquê de nenhum rio permanente originar-se no local;

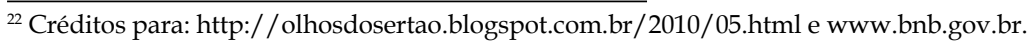


$\mathrm{S}$ indicando estação seca de verão; e H referindo-se à temperatura média anual superior a $18^{\circ}$, ouseja, temperatura elevada ${ }^{23}$.

O quadro climático descrito gera uma umidade relativa do ar que apresenta médias anuaispor volta de $50 \%$ e insolação que chega ao patamar de $2800 / \mathrm{h} /$ ano, marcado pela predominância deuma cobertura vegetal constituída de espécies decíduas e caducifólias, com forte presença decactáceas ${ }^{24}$. Como consequência, tem-se um elevado déficit hídrico que, segundo Rebouças(2001), chega a atingir $2200 \mathrm{~mm}$ /ano, inviabilizando algumas soluções hídricas, a exemplo dosaçudes, sempre tidos como solução para a problemática do semiárido ${ }^{25}$.

Muitos estudos tentam explicar a dinâmica da atmosfera em escala local, de modoa satisfazer, o que de fato ocorre com as precipitações no semiáridoe chega-se a atribuir a quase inexistência de entrada de frentes, como o principal fator que influencia o clima em pequena escala.

Conti e Furlan apontam a influência do relevo, tendo em vista que as áreas do Planalto da Borborema, transversal à direçãopreponderante dos ventos, provoca desvios significativos destes, com influência direta nasprecipitações ${ }^{26}$.

Outro aspecto a ser considerado é o El Niño-Oscilação Sul (ENOS) que, de forma geral, se constitui em um fenômeno de interação atmosfera-oceano, conexo a alterações dos padrões normais da temperatura da superficie do mar (TSM) e dos ventos Alísios na região do Pacífico Equatorial, entre a Costa Peruana e o Pacífico Oeste, adjacente à Austrália. Assim, valores negativos e positivos do Índice de Oscilação Sul (IOS) IOS são indicadores da ocorrência de El Niño e La Niña, respectivamente ${ }^{27}$.

De acordo com a mesma fonte, essas condições proporcionam uma intensificação dos movimentos ascendentes,

${ }^{23}$ DANNI-OLIVEIRA, I. M.; MENDONÇA, F. Climatologia: noções básicas e climas do Brasil. São Paulo: Oficina de Texto, 2007.

${ }^{24}$ AB' SABER, A. N. O domínio morfoclimático das Caatingas brasileiras. In: Geomorfologia. São Paulo: USP - Instituto de Geografia, 1974.

${ }^{25}$ REBOUÇAS, A. Água e desenvolvimento rural. Estudos Avançados, 15 (43) 2001.

${ }^{26}$ CONTI, J. B. e FURLAN, S. A. Geoecologia - o clima, os solos e a biota. In: ROSS, J. L. S. (org.). Geografia do Brasil. 2. ed. São Paulo: Edusp, 1998.

${ }^{27}$ CIRAM - Centro de Informações de Recursos Ambientais e Hidrometeorologia de Santa Catarina. Disponível em: <http://ciram.epagri.rct-sc.br:8080/cms/meteoro/el> Acesso em: 16 out. 2008. 
aumento da atividade convectiva e precipitação sobre a Indonésia e norte da Austrália, além de contribuir também para o aumento da atividade convectiva sobre a Amazônia e Nordeste semiárido brasileiro, caracterizando situações extremas de secas e/ou enchentes.

Também o fenômeno conhecido como Dipolo do Atlântico causa variação de precipitação no Nordeste do Brasil e na África. Esse evento é uma mudança anômala na temperatura da água do mar no Oceano Atlântico Tropical, altera a circulação meridional da atmosfera (célula de Hadley) e inibe ou aumenta a formação de nuvens sobre o Nordeste do Brasil e alguns países da África, diminuindo ou aumentando a precipitação ${ }^{28}$.

A estrutura geológica da área onde está situadaparte significativa do semiárido é constituída pelo embasamento cristalino do Planalto da Borborema, de idade Pré-Cambriana, no qual predominam gnaisses, migmatitos e granitos sob a formade inúmeros afloramentos ${ }^{29}$. Este aspecto, embora possa parecer irrelevante, inviabiliza as possibilidades de se obter água subterrânea, uma necessidade básica da área, devido ao substrato impermeável ${ }^{30}$.

Os solos, um recurso essencial no setor produtivo primário, são predominantemente litólicos, rasos e pouco desenvolvidos, com fraca capacidade de armazenar água. Os Neossolos Litólicos são, em geral, rasos,com espessura inferior a 0,50 m, e um estreitoperfil sobrea rocha, ocorrendo, mais frequentemente, em áreas de relevo acidentado. Também são solos comgrande potencial para aproveitamento hidroagrícola, embora necessitem de um manejo eficiente devido a sua tendência a salinização e a sodificação ${ }^{31}$.

\footnotetext{
${ }^{28}$ SOUSA, R. F., de. Geoprocessamento no estudo das terras com vista ao desenvolvimento sustentado, com diminuição dos riscos. $2007180 \mathrm{f}$. Tese (Doutorado em Engenharia Agrícola) Campina Grande, 2007.

${ }^{29}$ DANTAS, José Robison Alcoforado e CAÚLA, José Antonio Lopes. Mapa Geológico da Paraíba: Texto Explicativo, Campina Grande. Grafset, 1982.

${ }^{30}$ CPRM, Serviço Geológico do Brasil. Projeto cadastro de fontes de abastecimento por água subterrânea. Diagnóstico dos municípios do Estado da Paraíba. Organizado por: MASCARENHAS, J. C.; BELTRÃO, B. A.; SOUZA JUNIOR, L. C. de; MORAIS, F. de; MENDES, V. A. e MIRANDA, J. L. F. de. Recife: CPRM/PRODEEM, 2005.

${ }^{31}$ BRASIL, Secretaria de Desenvolvimento Territorial SDT/MDA - Estudo Propositivo para Dinamização Econômica do Território do Cariri (Versão Preliminar), 2005.
} 
A Cobertura Vegetal é do tipo Caatinga hiperxerófila, variando, de arbustivo esparso a arbustivo muito rala. Em vista disso, apresentam certo número de problemas quanto a sua definição eclassificação, em virtude de serem encontradas de maneira muito heterogênea, não só do ponto devista fisionômico, da sua composição florística e condições estacionais, como também, pelo longo período de ocupação humana, centrada na pecuária, na agricultura, na exploração mineral e noextrativismo vegetal ${ }^{32}$.

A estrutura fundiária do semiárido pode ser considerada a mais concentradora e fechada do mundo, pois sempre esteverelacionada aos latifúndios, devido ao fato de sua gênese derivar de uma aristocracia rural iniciadano período colonial, cuja atividade econômica principal esteve ligada à pecuária. Entretanto, com oavançar do tempo e a inevitável divisão por hereditariedade, hoje este aspecto concentrador deterras vem tendo como característica um grande número de estabelecimentos com área reduzida. Mesmo assim, os imóveis $>50$ ha - faixa na qual se concentra a maioria das propriedades - correspondem a $80 \%$ do total de estabelecimentos, mas ocupa apenas $15 \%$ da áreatotal, demonstrando que ainda há problemas na distribuição e posse das terras.

A convergência de todos estes aspectos faz com que a designação de seca se traduza num período prolongado de baixa pluviosidade ou sua ausência, em que a perda de umidade do solo é superior a suareposição e, por ser assim, pode ser considerado como um dos fenômenos naturais demaior ocorrência e impacto no mundo ${ }^{33}$. Já na visão dos protagonistas deste fenômeno, seca pode ser: falta de chuva e, não chovendo, não se tem o que comer; seca é um grande desastre. A partir da seca, acaba tudo. A terra vira deserto. Acaba a família. A seca acaba a pessoa, que se acaba de trabalhar ${ }^{34}$.

\footnotetext{
${ }^{32}$ ANDRADE-LIMA, Diva M. de; SILVA, Marlene Maria da. Sertão Norte: área do sistema gadoalgodão. Recife: SUDENE, 1982.

${ }^{33}$ KOBIYAMA, M.; MENDONÇA, M.; MORENO D. A. MARCELINO, I. P. V. de.; MARCELINO, E.; BRAZETTI, L. L. P., GOERL, R. F.; MORELI, G. S. F. e RUDORFF, F. M. Prevenção de Desastres Naturais: conceitos básicos. Curitiba: Ed. Organic Trading, 2006. p. 80 ${ }^{34}$ DUARTE, Renato. Pobreza, desigualdad social y ciudadanía: los límites de las políticas sociales em América Latina. In: CLACSO, A. Z. (Org.). Consejo Latinoamericano de Ciencias Sociales. Ciudad Autónoma de Buenos Aires, Argentina. 2001.
} 
Yná Andriguetti, mesmo utilizando outros termos em sua análise sobre as estruturas do Nordeste semiárido, corrobora a definição anterior, quando afirma que o conjunto destes fatores aumentaa vulnerabilidade da população,é o resultado e o acréscimo das desigualdades sociais e econômicas, produto de um determinado processo ao longo do tempo e do espaço, de modo que a velha estrutura de poder se mantenha inalterada ${ }^{35}$.

As ações empreendidas com vistas a resolver os problemas e viabilizar a convivência com a estiagem neste compartimento do Brasil não apenas mantiveram inalterado o status quo, como também destas iniciativas tirou-se proveito, como mostram os fatos que se seguem.

\section{O semiárido e as políticas públicas: causas e consequências}

As secas já eram conhecidas desde 1553, quando Fernão Cardim registrou a estiagem que assolou a Bahia, reduzindo a produção dos engenhos de açúcar e forçando muitos indígenas a se abrigarem no litoral. Assim mesmo, o fenômeno só ganhou notoriedade no Brasil com o grande flagelo dos anos 18771879, que abalou o semiárido brasileiro, à época esquecido e vagamente designado como Norte. Naquela estiagem pereceram pelo menos 500 mil nordestinos, com 200 mil mortes somente no Ceará, na mais otimista das visões, $4 \%$ da população do Brasil $^{36}$.

Segundo este mesmo autor, no final dos anos de 1850, ao tempo de completar duas décadas do segundo império, foi criada uma comissão científica composta por uma leva de personagens ilustres e influentes em diversas áreas e cuja incumbência era explorar e conhecer a região problemática do país.

Entre as conclusões da célere comissão está: (i) imputar aos nordestinos a responsabilidade pelo maleficio gerado pelas secas, uma vez que a estes faltava destreza e disposição para o trabalho; (II) desconhecimento de técnicas agrícolas que melhor aproveitasse os recursos disponiveis; e (iii) sugerir a importação

${ }^{35}$ ANDRIGUETTI, Y. Nordeste: mito \& realidade. 6 a . Impressão. São Paulo: Moderna, 2003, 176 p. Coleção Polêmica.

${ }^{36}$ VILLA, op. cit., p 13-14. 
de camelos, como forma de solucionar a problemática do deslocamento e transporte de carga, valendo-se da característica peculiar do dromedário que exige pouca água para sobreviver ${ }^{37}$.

Em 1860, o Barão de Capanema elaborou um relatório de avaliação das obras de combate às secas, defendendo a construção dos açudes, mas somente quando construídos em lugares convenientes àprática de atividades hidroagrícolas. Ocorre que estes lugares convenientes no semiárido são as várgeas e, segundo Naziz Ab'Saber ${ }^{38}$, este tipo de área agrícola no semiárido é de pouca ocorrência. Não obstante essa oportuna observação, os açudes foram sendo construídos tendo-se por base feições topográficas e/ou influências políticas locais, a tal ponto que açudes de bilhões de $\mathrm{m}^{3}$, como Orós (CE), afora a maior extensão de terras irrigáveis do vale do Jaguaribe, quase nada foi investido no capital humano para torná-lo apto a usar e melhorar novas tecnologias de manejo adequado do binômio solo-água ${ }^{39}$.

Culturalmente, os açudes e poços no semiárido brasileiro foram construídos visando ao abastecimento das populações e dos rebanhos. Tal circunstância contribuiu para a manutenção de um contexto de má utilização que estabelece claro contraste com o grande volume de água armazenadoe o potencial valorizável. Nessa situação, registra-se anualmente perda por evaporação da água dos açudes, que representa uma lâmina d'água média ao redor de $2 \mathrm{~m}^{40}$.

No Século XX, já no regime republicano, foram impulsionadas algumas politicas por parte do Estado, visando à atenuação do fenômeno, que consistiram na institucionalização da questão da seca, mediante a criação de órgãos de planejamento regional. Para que isso fosse possivel, o governo federal criou uma dotação orçamentária e instalou três comissões: a de açudes e irrigação, a de estudos e obras contra os efeitos da seca e a de perfuração de poços ${ }^{41}$.

\footnotetext{
${ }^{37}$ Ibidem, $\mathrm{p} 26$.

${ }^{38}$ AB'SÁBER, A. N Os domínios de natureza no Brasil: potencialidades paisagísticas. São Paulo: Ateliê Editorial, 2003.

${ }^{39}$ REBOUÇAS, A da C. Água na Região Nordeste: desperdício e escassez. Estudos Avançados, v. 11, n. 29, 1997, p. 127-154.

${ }^{40}$ Ibidem.

${ }^{41}$ POMPONET, A. S. Cem anos de DNOCS: marchas e contramarchas da convivência com as secas. Conj. \& Planej., Salvador, n.162, p.58-65, 2009
} 
Das três, apenas uma permaneceu, a de açudes e irrigação. Entretanto, tal comissão não teve um desempenho satisfatório e ensejou a criação da Inspetoria de Obras Contra as Secas, em 190942. Em 1919, o referido órgão foi transformado na Inspetoria Federal de Obras Contra a Seca - IFOCS, que em 1945deu origem ao Departamento Nacional de Obras Contra a Seca - DNOCS, inspirado nos modelos gestão norte-americanos e australianos.

A política para a região, portanto, era a de construir imensos reservatórios artificiais de água, embora as obras não entusiasmassem os oligarcas locais, temerosos da modernização do Sertão e da erradicação da miséria que constituía seu principal capital politico ${ }^{43}$.

Ao comentar o desempenho dos órgãos criados, destinados aexecutar a política hídricado semiárido, Yná Andriguetti cita que cada um deles, a seu tempo, procurou definir metas de trabalho. O IOCS concluiu que a melhor solução seria estabelecer uma política de armazenamento de água para suprir a população e a agricultura, nos momentos de escassez. O IFOCS, por sua vez, desenvolveu um estudo detalhado sobre as potencialidades do clima, do solo e da vegetação, bem como deu início à construção de açudes e barragens. Já o DNOCS surgiu com metas mais amplas, propondo-se a combater a seca em qualquer parte do país. Contudo, sua atuação se restringiu ao semiárido, sendo desde cedo dominado pela elite política oligárquica regional ${ }^{44}$.

Dessa concentração de poder, autores ligados ao tema levantam algumas reflexões acercada condução da política de recursos hídricos do Nordeste. Cláudia Bezerra e Janete Lins Rodriguez mostram que todas as decisões partiam de políticos/ latifundiários, os quais sempre submeteram a maior parcela da população aos seus interesses, controlando o aparelho político-administrativo ${ }^{45}$.

\footnotetext{
${ }^{42}$ SUASSUNA, J. Semiárido: proposta de convivência com a seca. Fortaleza: Fundação Konrad Adenauer, 2002, p. 2

${ }^{43}$ POMPONET, A. S. Cem anos de DNOCS: marchas e contramarchas da convivência com as secas. Conj. \& Planej., Salvador, n.162, p.58-65, 2009

${ }^{44}$ ANDRIGUETTI, Y., op. ci.t, p.16.

${ }^{45}$ BEZERRA, C. P. e RODRIGUEZ J. L. Conhecendo o Cariri. Recife: Gráfica Liceu, 2000.
} 
Mariano Neto destaca que o problema social dos currais eleitorais (as cercas) talvez seja tão grave quando o problema das secas. Para o citado autor, essa metáfora se cristaliza na cultura da apropriação da água, por exemplo, onde a mentalidade do ter põe por terra qualquer projeto racional, seja local ou regional. Neste sentido, concluiu o autor: "ainda prevalece nos proprietários e seus herdeiros valores que são próprios dos antigos donatários"46.

Assim, a prioridade foi a implantação do Programa Açudes, com capacidade suficiente para ultrapassar um período de seca aproveitando-se das características geológico/geomorfológicas da região, possibilitando a construção de um número expressivo de açudes e barragens, estimados em mais de 70.000 (setenta mil) unidades, que represam cerca de 30 bilhões de $\mathrm{m}^{3}$ de água, representando a maior reserva superficial artificialde água em regiões semiáridas do mundo. Porém, apenas $30 \%$ desse volume era utilizado na irrigação e no abastecimento das populações, consubstanciando-se numa evidente falta de planejamento na gestão dos recursos hídricos da região ${ }^{47,48}$

Como consequência, as politicas de combate aos efeitos das secas, notadamente sob auspícios do Dnocs, embora não se possa desprezar sua importância no conhecimento acumulado sobre as condições físicas e climáticas da região ao longo do tempo, jamais foram efetivas no enfrentamento do principal problema decorrente da estiagem prolongada: o da criação de condições de trabalho e, portanto, de geração de fontes de emprego e renda em niveis mínimos e permanentes para a grande massa de pessoas que habitam os sertões nordestinos ${ }^{49}$.

Para estes autores, "os açudes construídos pelo Dnocs, embora tenham tido papel importante no combate aos efeitos

\footnotetext{
${ }^{46}$ MARIANO NETO, B. Ecologia e Imaginário. João Pessoa: Editora Universitária, 2001.

${ }^{47}$ SUASSUNA, op. cit., passim.

${ }^{48}$ Este aspecto só se tornaria favorável à democratização da distribuição dos recursos hídricos após a instituição da Lei federal 9433/97, que disciplinou o uso e a gestão e tornou a água um bem público.

${ }^{49}$ KHAN, A. S.; CRUZ, J. A. N. da.; SILVA, L. M. R. e LIMA, P. V. P. S. Efeito da Seca sobre a Produção, a Renda e o Emprego Agrícola na Microrregião Geográfica de Brejo Santo e no Estado do Ceará. Documentos Técnico-Científicos. Revista Econômica do Nordeste, Fortaleza, v. 36, n. 2, 2005.
} 
das secas, permitindo a acumulação de grande volume de água, não são suficientes para evitar que a tragédia se repita cada vez que as chuvas faltava na região".

Neste contexto, o DNOCS mostrou-se incapaz de romper a lógica que o subordinou aos interesses dos latifundiários e coronéis regionais. Esse sistema configurou-se numa verdadeira fábrica de votos, embora a lisura não fosse uma característica das eleições, reforçando o vicioso ciclo da indústria das secas.

Conforme estes mesmo autores: "os pactos políticos, ainterpretação equivocada da realidade, a manutenção do status quo e o descaso com que, frequentemente, o semiárido é tratado explicam a derrocada das políticas aplicadas ao longo do século XX". Como remédio a essa situação, o projeto que instituiua Superintendência de Desenvolvimento do Nordeste (SUDENE) colocava o DNOCS sob a supervisão desse órgão, extinguindo seu papel na execução de obras.

No início da década de 1950, o reducionismo com que são tratados os aspectos da seca nordestina começou a mudar profundamente. A proposta de criação do Banco do Nordeste do Brasil (BNB) surgiu fortemente associada à ideia de mudança na forma de perceber o problema nordestino. De um lado, ampliou o campo de visão, ao introduzirem-se os aspectos econômicos comorelevantes para a compreensão do problema e a busca de soluções para a região. E de outro, rompendo a limitação da análise focada apenas no problema da seca.

Ainda de acordo com estes autores:

$\mathrm{O}$ aspecto mais importante relacionado com a criação do BNB é que essa iniciativa representou um marco da mudança de atitude do governo federal em relação ao problema do atraso relativo do Nordeste. Abandonavam-se as diagnoses focadas no enfrentamento das secas periódicas com obras hidráulicas e de engenharia e introduziam-se os fatores econômicos como aspectos centrais do problema. Ao mesmo tempo, reconhecia-se, nos diagnósticos e nas propostas de soluções, a necessidade do aproveitamento das potencialidades econômicas da região ${ }^{50}$.

Quanto a SUDENE, em que pese à região Nordeste ter logrado êxito na economia industrial nos últimos anos, com

\footnotetext{
${ }^{50}$ Ibidem, p. 248
} 
crescimento acima da média nacional e ter conseguido avanços técnicos em seu parque industrial, a economia continua profundamente dependente das regiões mais dinâmicas do país.

O modelo produtivo como elemento dinâmico de impulso à industrialização legitimou as desigualdades, na medida em que os beneficiários do crescimento industrial foram às grandes empresas, o capital (nacional e multinacional) que se expandiram em direção ao Nordeste, dispostos a aproveitar o sistema de incentivos, pelas matérias-primas locais ou pelo mercado consumidor da região, a segunda mais populosa do país ${ }^{51}$.

Para muitos estudiosos, a industrialização levada a efeito pela SUDENE ${ }^{52}$ criou a falsa expectativa de absorver a mão-de-obra desqualificada da região, atraindo para a periferia das grandes e médias cidades um contingente populacional oriundo das áreas rurais da própria região.

Quanto ao setor agrícola, as diretrizes consistiam em medidas de reorganização do semiárido, na diversificação da zona canavieira e na abertura de frentes de colonização no Maranhão. Segundo a economista Tânia Barcelar de Araújo, tal pretensão deparou-se com diversos obstáculos, o principal deles foi o arquivamento das propostas de mudança na estrutura fundiária, na vigência da ditadura militar ${ }^{53}$.

Nas palavras da Autora:

Ao invés de uma agricultura diversificada, para atender ao mercado local, surgem no Semiárido diversos pontos de concentração de uma moderna agricultura irrigada, voltada para o mercado externo. Nesse caso, a atuação do Estado foi fundamental, uma vez que montou a maior parte da infraestrutura de captação e distribuição de água, ou seja, enquanto tais políticas patrocinavam a modernização da algumas atividades, promoviam o desaparecimento de outras, como o fez com a inviabilização da policultura no Agreste, atingindo os pequenos

${ }^{51}$ DIAS, A. B. Em tempos de SUDENE: ouvidos e olvidos. Revista de Economia do Nordeste v.30 n. Especial p. 840-855. Recife, dez.1999. Disponível em: <www.fundaj.gov.br> Acesso em: 12 de setembro de 2007.

${ }^{52}$ ANDRADE, M. C. de. O Nordeste e a questão regional. São Paulo: Ática, 1993, p.53

${ }^{53}$ ARAÚJO, T. B. Herança de diferenciação e futuro de fragmentação. Estudos Avançados, v. 11, no. 29,1997, p.66. 
produtores, que migraram para as cidades se expondo aos riscos já mencionados ${ }^{54}$.

Some-se a tudo issoa crise do algodão (com a presença do bicudo e as alterações na demanda, no padrão tecnológico da indústria têxtil) um peso expressivo na ampliação da vulnerabilidade econômica da população do espaço agrário nordestino.

Segundo a referida autora, no contexto local, o algodão era a principal fonte de renda dos trabalhadores rurais do semiárido. Na ausência do produto, eles eram obrigados a levar ao mercado o pequeno excedente da agricultura alimentar tradicional de sequeiro (feijão, milho e mandioca), reduzindo drasticamente sua reserva alimentar nos períodos mais secos ${ }^{55}$.

No que tange à pecuária, esta recebeu os créditos da SUDENE para consolidar (ao invés de reformar) a velha estrutura fundiária dessa sub-região nordestina, ou seja, os incentivos à pecuária, promovidos pelo órgão em análise, fortaleceram e modernizaram tal atividade, mas assentada em velhos conceitos.

A hegemonia crescente da atividade pecuária nos moldes em que foi realizada agravou a questão fundiária no Nordeste como um todo, além de provocar outros efeitos importantes, como a redução da produção de alimentos e a intensificação da emigração rural. Acrescente-se o fato de que a estrutura fundiária do Nordeste ainda permanece praticamente intocada, apesar da miséria alarmante dominante nas áreas rurais da região ${ }^{56}$.

Outros programas foram institucionalizados, em sua totalidade visando atenuar e contribuir para a convivência com as secas, melhorando a produtividade e, a reboque, a resolução de problemas, como flagelo, fome, êxodo, entre outros. Assim, a partir de 1968, foi realizado vasto estudo depossibilidade de irrigação do Nordeste Semiárido. Em 1970, ano de intensa seca, criou-se o Programa de Integração Nacional (PIN), que resultou no Plano Nacional de Irrigaçãoque visava, em caráter de urgência, executarprogramas de irrigação. Depois, veio o Programa de Redistribuiçãode Terras e Apoio à Indústria Canavieirae o Programa Plurianual de Irrigação. A ideia era complementar

\footnotetext{
${ }^{54}$ Ibidem, p.170.

${ }^{55}$ Ibidem, p.177.

${ }^{56}$ ANDRADE, op. cit.,.p.49.
} 
as ações realizadas durante afase hídrica, aproveitando a água acumulada, e promovera agricultura irrigada ${ }^{57}$.

Em 1971, com o Primeiro Plano Nacionalde Desenvolvimento (I PND), o PIN e seus objetivos específicos foram incorporados, mas a ênfase dada era para a desapropriação de terras e concessãode créditos fundiários de longo prazo para compra de terras. Porém, com o II PND, em 1974, abandonou-se a estratégia do plano anterior, acabando-se com oPIN e seus recursos foram destinados para novos programas: o Programa de Desenvolvimento de Áreas Integradas do Nordeste (Polonordeste) e o Projeto Sertanejo, que contaram com o apoio dedois grandes aliados: o Banco Interamericano de Desenvolvimento (BID) e o Banco Internacional de Reconstrução e Desenvolvimento (BIRD). Com essas iniciativas, deu-se, assim, início a outro ciclo: o do desenvolvimento rural integrado ${ }^{58}$.

Contudo, em que pese todo o discurso de alavancar a agricultura no semiárido, priorizando a produção para o mercado externo e o implemento da atividade pecuária, as politicas governamentais, assentadas sobre as velhas estruturas, não só não resolveram a problemática, como alargaram as demandas da população, cada vez mais desassistida.

As novas iniciativas que se sucederam misturaram ações emergenciais, desenvolvidas durante anos de seca, com ações permanentes. Os esforços para desenvolver o Nordeste semiáridotambém não proporcionaram os resultados esperados. Portanto, os problemas da pobreza, desequilíbrios sociais e atraso econômico estão ainda por serem superados, bastando observar as últimas ocorrências do fenômenocitado ${ }^{59}$.

O Governo Federal buscou também soluções para a problemática suscitada pelas secas, naquele que é um setor da economia da região, de extrema relevância, devido ao seu papel, no que se refere ao sustento da população humana, assim como aos rebanhos, consubstanciado nos recursos vegetais.

\footnotetext{
${ }^{57}$ KHAN, op. cit.

${ }^{58}$ Ibidem.

${ }^{59}$ Citado por: KHAN, op. cit.

154 Revista de História Regional 17(1): 135-161, 2012
} 
Assim sendo, o primeiro plano de reflorestamento, realizado no final dos anos sessenta foi de significativo impacto social e merecedor de profunda análise política, econômica e ambiental. Esteprojeto fez parte da política de modernização realizada no semiárido causando prejuízos tão sérios, que podem mesmo ser considerados casos de improbidade. O mais grave destes foio reflorestamento com a algaroba (Prosopisjuliflora) uma espécie originária dos Andes e que fora introduzida no ambiente sem nenhum conhecimento prévio do seu comportamento biológico.

Ligado aos propósitos do desenvolvimento da agricultura nacional, o reflorestamento levado a cabo pela ditadura militar não se propunha a alterar a estrutura fundiária concentradora do semiáridoporque considerava que a grande unidade fundiária era superior, no sentido técnico e econômico, à pequena exploração de base essencialmente familiar ${ }^{60}$.

Dessa forma, o intuito legal da política de reflorestamento com algaroba já evidenciava o sentido excludente e mesmo irresponsável da política governamental de reformar a paisagem aparentemente desoladora da região.

Os recursos eram contratados a fundo perdido, ou seja, os financiamentos não precisavam ser devolvidos aos cofres públicos e o órgão de financiador dessa política foi o Fundo de Investimento Setorial (FISET) e o Instituto Brasileiro de Desenvolvimento Florestal (IBDF), que realizavam vistorias para verificar a consistência dos projetos e as áreas em que se pretendia implantá-los.

O financiamento ainda obedecia a mais duas fases, a do plantio e, posteriormente, a de manutenção, para que se completasse todo o repasse dos recursos. O que mais chamou a atenção nessa ação modernizante foi à seletividade que se procedeu no que refere ao tamanho de cada propriedade a ser desmatada e, posteriormente, reflorestada ${ }^{61}$.

$\mathrm{O}$ autor aqui mencionado descreve o contexto em que o financiamento era efetivado: "foi uma festa, proprietários com mais de 100 hectares se qualificavam, desmatavam a caatinga

${ }^{60}$ DUARTE, J. J. A nova paisagem do Semiárido no contexto da modernização: o caso da Algaroba. Revista da Adufpb. João Pessoa, 2000.

${ }^{61}$ Ibidem. 
nativa, plantavam abundantemente a algaroba e receberiam vultosas somas para cuidar dos seus campos".

Não satisfeito com a primeira investida e influenciado pela grande seca nordestina de 1979 a 1983 e pelo bom desempenho da algaroba no semiárido brasileiro, o Governo Federal realizou uma segunda versão, denominada de Projeto Algaroba no período de 1985 a 1988. Esse projeto consistiu na produção e distribuição de mudas de algarobeiras, prestação de assistência técnica e apoio financeiro aos produtores ${ }^{62}$.

O Projeto Algaroba foi realizado utilizando recursos do FINSOCIAL e do BNDES e coordenado pela Secretaria Nacional de Produção Agropecuária (S N A P), do Ministério da Agricultura, com a participação das Secretarias de Agricultura dos Estados do Nordeste.

Segundo esse mesmo autor, o Projeto Algaroba atendeu 8,3 mil pequenos produtores rurais na implantação de 18,8 mil hectares em 540 municipios da área da SUDENE.

O resultado dessa ação se revela hoje num problema de grande espectro,pois a espécie se desenvolve sem qualquer controle, em proporção espantosa, prejudicando diversos aspectos, tanto nas atividades produtivas, quanto nos impactos ocasionados pela diversidade da Caatinga, aumentando assim as vulnerabilidades da região semiárida ${ }^{63}$.

Após a enumeração de políticas (no tocante à atenuação dos efeitos da seca para a maioria da população - a classe menos favorecida) já abordadas, o Estado enquanto instituição, atendendo aos anseios de uma classe de trabalhadores rurais, não contribuintes diretos da Previdência, criou o Fundo de Assistência e Previdência Rural - FUNRURAL. Para sustentar o fundo, criou também uma Contribuição Previdenciária destinada ao Custeio a Previdência Rural.

Com a efetivação destas mudanças previdenciárias estendidas ao setor rural, os proprietáriosde terras passaram a

\footnotetext{
${ }^{62}$ BACHA, J. C. Reflorestamento no Brasil. Revista análise econômica. ano 10, n.17, Porto Alegre, 1992, p. 143.

${ }^{63}$ PEREIRA, R. A. Impactos ambientais decorrentes das condições antroponaturais no município de São João do Cariri - PB. Campina Grande: UFCG, 2008. 106f. (Dissertação de Mestrado).
} 
estimular a transferência de seus moradores para as cidades. Essa facetaderiva do fato de que os donos de propriedades rurais estavam fugindo do ônus de honrarem tais encargos sociais, que na realidade, sustentariam a previdência rural. Em face desta migração, passou a existir nas cidades um grande processo de favelização, visto que os serviços oferecidos exigiam certo grau de especialização, fato que inexistia nesta população oriunda do campo ${ }^{64}$.

Para este autor, essas ações, aos poucos vêm decretando a extinção de uma classe de pequenos agricultores, meeiros, posseiros que passam a condição de assalariados nas periferias das cidades, transformando-se num problema social de grande magnitude para as instituições.

$\mathrm{Na}$ atualidade, as aposentadorias rurais podem ser consideradas fonte de renda para uma faixa considerável da maioria dos municípios do semiárido. Esse fato é reconhecido até mesmo pelo Ministério da Previdência Social, que declara: no contexto climático e socioeconômico adverso da região do semiárido brasileiro, a Previdência Social tem garantido renda mensal a 2,6 milhões de pessoas mediante o pagamento de beneficios a trabalhadores urbanos (717 mil) e rurais (1,9 milhão), o que significou, em junho de 2001, um gasto da ordem de $\mathrm{R} \$ 512,9 \mathrm{mi}$ 1hões ${ }^{65}$. Isso apenas para citar como exemplo o ocaso do governo FHC, reconhecido como um dos maiores arrochos salariais da história recente do País.

Outra prática assistencialista concebida pela União, ainda no governo supracitado e, sem prejuízo do recebimento do beneficio mencionado, teve como base o incentivo ao engajamento da população em manterem seus filhos em idade escolar, com frequência regular na escola. Em troca recebiam (e ainda recebem) uma bolsa mensal que, embora não tenha sido exclusiva para amparar as vítimas das secas do Nordeste semiárido, tem aliviado a pressão sobre o meio ambiente nas

\footnotetext{
${ }^{64}$ ANDRADE, op. cit., p. 25

${ }^{65}$ BRASIL, MINISTÉRIO DA PREVIDÊNCIA E ASSISTÊNCIA SOCIAL. Informativo mensal da secretaria de comunicação, n.8, Brasília, 2001. Disponível em: <www.mpas.gov.br>. Acesso em: 01 de julho de 2006.
} 
zonas de ocorrência da estiagem, uma vez que desobriga os mais carentes a buscarem no extrativismo vegetal (extração predatória da madeira para lenha e carvão), preservando a cobertura vegetal da área, tão intensamente afetada ${ }^{66}$. Embora seja prematura uma análise desta nova modalidade de assistência, em virtude do espaço-tempo em que está em vigor, há também que ser considerada a possibilidade, nem tão remota assim, de solução de continuidade, o que pode inviabilizar qualquer chance de êxito desta ação, haja vista ser este um indicador de situação ${ }^{67}$.

Seja pelo dispêndio das aposentadorias, seja pela concessão das bolsas, o fato é que a população do Nordeste semiárido ainda continua a depender, e muito da muleta estatal para sobreviver e este fato se deve em muito às ações e omissões de uma elite que soube como em poucos lugares tirar proveito, não somente das condições adversas: climáticas, econômicas ou sociais, mas apoderou-se habilmente das providências no intuito de minorá-las.

\section{Considerações finais}

As politicas públicas, visando diminuir as desigualdades intra e inter-regionais em relação ao Nordeste semiárido e/ou as demais regiões do país, têm, ao longo das décadas, servido para uma série de ações, cujos resultados só beneficiam as elites e o capital. Além disso, muitas destas lideranças locais, quando ocupam cargos públicos, mostram um lado subserviente ao poder central, em detrimento dos interesses de sua região, cujo histórico remonta aos tempos mais imemoriais.

Poucas foram as políticas que tiveram como foco o desenvolvimento dos estados nordestinos e mais raras ainda quando se trata de semiárido. Menores ainda foram os resultados positivos alcançados por tais políticas. Prova disso

\footnotetext{
${ }^{66}$ PEREIRA, R. A.; MELO, J. A. B. de.; DANTAS NETO, J.; BARBOSA, E. M. Análise do comportamento espectral da cobertura vegetal de São João Do Cariri-Pb no espaço temporal de vinte anos (1987 - 2007), sob condições diversas de utilização. Caminhos de Geografia, Uberlândia, v. 11, n. 36 dez/2010 p. 68 - 80.

${ }^{67}$ MATALLO Júnior, H. Indicadores de Desertificação: histórico e perspectivas. Brasília: UNESCO, 2001.
} 
está no desempenho logrado pela SUDENE, pelo DNOCS no incentivo à Açudagem ou à Agricultura familiar. Atualmente, em pleno Século XXI, testemunham-se a aflição das populações humanas, a escassez de água e alimento para os rebanhos frente a estiagem que se vivencia. E aí o foco da mídia muda: ao invés das festas e do turismo praia e sol, a tragédia, o drama, tudo de novo!

A explicação mais plausivel para tantos fracassos está nas estruturas, tanto político-social, quanto fundiária que dificultam sensivelmente qualquer mudança de rumo das ações que beneficiem a maior parcela da população.

A questão do coronelismo, do curral e do voto de cabresto, quando o poder local determina onde e como fazer mesmo que velada, ainda sobrevive. O desastre da seca, em determinado contexto da política local no Nordeste, torna-se um instrumento valioso na manutenção e perpetuação do poder nas mãos de poucos.

Assim, o cenário do Nordeste (semiárido principalmente) nas demais regiões brasileiras é deprimente (mas poderia ser diferente) e só se transformará no momento em que houver representações institucionais sérias, que tratem a questão nordestina na extensão de sua magnitude. Entretanto, para que isso ocorra, será necessário que a sociedade invista nela própria, por intermédio da formação de capital humano e social, de modo que possibilite reivindicar ações políticas e instituições comprometidas com a boa governança.

A despeito dos avanços econômicos conseguidos pela região Nordeste, no tocante às secas, velhas estruturas ainda permanecem atuantes, mormente no poder central e que acabam por colocar práticas corporativas à frente dos interesses da coletividade, o que justifica plenamente a impressão de Marco Antonio Villa, 'este é um assunto ainda vivo e um incômodo para as elites'.

Resumo: A colonização da costa leste do Continente sul-americano se efetivou na faixa marginal ao Atlântico. A ausência do principal objetivo do colonizador, metal precioso, neste território, fez com 
que a Coroa consolidasse a ocupação, por meio do extrativismo e do Engenho. Dada a importância do açúcar, a Metrópole cuidou em proteger o espaço ocupado pela cana-de-açúcar contra a concorrência de quaisquer outras atividades produtivas, ensejando o povoamento e a prática de outro modo de produção, por intermédio do Curral. A partir daí, desencadeou-se um processo de exploração dos recursos da zona semiárida, que nos dias atuais, beira a exaustão. A seca, evento cíclico na área, conta com registro a partir de meados do Século XVI e, a cada ocorrência, degrada e dizima. No interior da região, as elites souberam como utilizar as mazelas da seca e como tirar proveito das providências para sua mitigação. Com isso, surgiram nesta área alguns aspectos que se conservam até os dias atuais. Em vista destas questões, este ensaio teve como objetivo analisar algumas das políticas públicas que tiveram como finalidade a viabilidade do Nordeste, enquanto região econômica, em particular o Semiárido nordestino, e elencar alguns fatores e ações decisivos para a construção dos cenários observados até os dias de hoje.

Palavras-chave: Poder local. Secas. Degradação.

Summary: The colonization of the East Coast of the South American continent took place along the Atlantic shoreline. The absence of the main objective of the colonizer in this territory, the precious metal, has prompted the Crown to consolidate the occupation through extractivism and milling. Given the importance of the sugar, the Metropolis took measures to protect the areas destined to the production of sugar cane against competition from other productive activities, enabling the population of the region and the practice of another mode of production through the "corral". This has marked the beginning of a process of exploitation of the semiarid zone, which nowadays is on the brink of exhaustion. In the semiarid, the drought is a cyclical event that has been registered since the mid-sixteenth century and that continuously degrades and depletes the area. In the inland, the elites knew how to use the problems of the drought for their own benefit, and how to take advantage of the measures for its mitigation. This has helped the development of certain aspects that remain to this day. In view of these issues, this essay aims at analyzing some of the policies that sought to secure the viability of the Northeast as an economic region, with special attention to the semiarid, while 
ranking some factors and decisive actions that have developed the scenarios witnessed to this day.

Keywords: Local government. Drought. Degradation.

Artigo recebido em: 03/11/2011

Artigo aprovado para publicação em: 19/06/2012 